Check for updates

Cite this: RSC Adv., 2017, 7, 37039

\title{
Surface-enhanced Raman spectroscopy combined with gold nanorods for the simultaneous quantification of nitramine energetic materials
}

\author{
Burcu Guven, $\dagger^{\mathrm{a}}$ Merve Eryilmaz, (D) $\dagger^{\mathrm{b}}$ Ayşem Üzer, ${ }^{\mathrm{c}}$ Ismail Hakki Boyaci, ${ }^{\mathrm{a}}$ \\ Uğur Tamer ${ }^{* b}$ and Reşat Apak (D)*c
}

In this study, we propose a surface-enhanced Raman spectroscopy (SERS)-based method for the quantification of nitrite $\left(\mathrm{NO}_{2}{ }^{-}\right)$derived from the alkaline hydrolysis of explosive materials, octahydro1,3,5,7-tetranitro-1,3,5,7-tetrazocine (HMX) and hexahydro-1,3,5-trinitro-1,3,5-triazine (RDX). For this purpose, samples were hydrolyzed and neutralized before SERS measurement. The SERS determination of nitrite was performed on the surface of 4-aminothiol-modified gold nanorods doped with silver nanoparticles. Due to the differential hydrolysis behaviour of HMX and RDX at different alkalinities and temperatures, these two nitramines could be separately determined with SERS. Calibration curves were obtained for HMX and RDX by plotting the maximum intensity band at $1286 \mathrm{~cm}^{-1}$ (arising from diazotization of nitrite) versus the concentration of standard solutions. This correlation was found to be linear within the concentration range of $0.25-10 \mathrm{mg} \mathrm{L}^{-1}$, and the limit of detection of the method was $0.39 \mathrm{mg} \mathrm{L}^{-1}$ and $0.61 \mathrm{mg} \mathrm{L}^{-1}$ for RDX and HMX, respectively. Both sensitivity and linearity were better than in similar SERS assays. The proposed SERS method was validated against UV-vis colorimetric method, and the effectiveness of the method to quantify HMX and RDX in real soil samples was investigated. This is the first study on the simultaneous quantification of HMX and RDX in synthetic solutions and real samples by SERS. It may also serve to quantify HMX, emerging as a major impurity in commercial grade RDX samples.

Received 24th May 2017

Accepted 19th July 2017

DOI: $10.1039 / c 7 r a 05844 f$

rsc.li/rsc-advances

\section{Introduction}

The analytical relevance of explosives detection has been shown in different areas: counter-terrorism applications in homeland security, identification of explosive residues in the forensic field, quality control and safe storage of products in industry and military, and prevention of poisoning in environmental

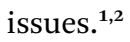

Octahydro-1,3,5,7-tetranitro-1,3,5,7-tetrazocine (HMX) and hexahydro-1,3,5-trinitro-1,3,5-triazine (RDX) are two leading nitramine compounds that are currently being used in weapon systems. RDX and HMX are the major/minor constituents in nearly every ordnance formulation (especially in plastic explosives) and are the secondary explosives used in greatest quantities. HMX has greatly replaced its homologue RDX in explosive formulations partly due to its higher resistance to undesired

\footnotetext{
${ }^{a}$ Department of Food Engineering, Faculty of Engineering, Hacettepe University, Ankara, Turkey

${ }^{b}$ Department of Analytical Chemistry, Faculty of Pharmacy, Gazi University, 06330, Ankara, Turkey. E-mail: utamer@gazi.edu.tr

${ }^{c}$ Department of Chemistry, Faculty of Engineering, Istanbul University, 34320, Istanbul, Turkey. E-mail: rapak@istanbul.edu.tr

$\dagger$ Equal contribution.
}

detonation, thus it became more commonly used in the area. Various determination methods for nitramines (basically RDX and HMX) have been developed using spectroscopy, ${ }^{3,4}$ capillary electrophoresis, ${ }^{5,6}$ gas chromatography, ${ }^{7-10}$ high performance liquid chromatography (HPLC), ${ }^{\mathbf{1 1 - 1 4}}$ ion mobility spectrometry ${ }^{\mathbf{1 5}}$ and voltammetry. ${ }^{16-18}$

Although environmental analyte detection has greatly improved in terms of accuracy, selectivity, sensitivity and analytical, ${ }^{19}$ the detection of explosive compounds residues is still a challenge, so techniques which are able to identify explosives from stand-off distances are in demand to guarantee personal safety. ${ }^{20}$ In order to prevent undesirable situations, laser-based optical techniques are chosen specifically for qualitative analysis. $^{\mathbf{2 0}}$

Raman spectroscopy has a considerable potential in highly selective, sensitive and rapid analysis of analytes. Its well-known advantages lie in the fact that Raman spectroscopy enables nondestructive analysis and gives specific molecular fingerprint of substances. However, HMX and RDX have quite similar structures, and therefore cannot be simultaneously quantified with SERS, therefore the non-destructive character of SERS in nitramines quantification should be understood with the reserve that RDX and HMX have to undergo differential hydrolytic degradation before the SERS detection of their hydrolysis product, nitrite. 
For the detection of explosives such as HMX, RDX, trinitrotoluene (TNT), triacetone triperoxide (TATP) and pentaerythritol tetranitrate (PETN), stand-off Raman measurements have been performed at $50 \mathrm{~m}$ and $55 \mathrm{~m} .^{21,22}$ In another study carried out in sealed plastic and glass containers, chemical weapon agent simulants have been detected at a distance of $6.7 \mathrm{~m}$ with Raman spectroscopy. ${ }^{23}$ Several explosives like nitroguanidine, HMX, RDX and their mixtures have been tested for remote sensing with optical fibers using a Raman spectrometer with a $514.5 \mathrm{~nm}$ laser. $^{24}$ In addition, 28 explosives were detected with coherent anti-Stokes Raman spectroscopy, ${ }^{25}$ and in another study the Stokes Raman spectra of 23 explosive compounds were compared with the antiStokes Raman spectra at $830 \mathrm{~nm}$ and $785 \mathrm{~nm}$ excitation wavelengths using optical fibers. ${ }^{26}$ Moreover, spectral Raman imaging techniques have been preferred to detect explosive particles. As an improvement of the identification of explosives, a combination of laser-induced breakdown spectroscopy (LIBS) and Raman spectroscopy ${ }^{27,28}$ has been performed to obtain 2D images of RDX, TNT, PETN and 2,4-dinitrotoluene (DNT). ${ }^{\mathbf{2 9}, 30}$ All mentioned studies above are related to the identification of explosive compounds with Raman spectroscopy. However, quantification methods are very limited; stand-off Raman spectroscopy was applied at distances of 5-9 $\mathrm{m}$ to perform qualitative and quantitative analysis of ammonium nitrate (AN) and PETN. ${ }^{31}$

Surface-enhanced Raman scattering (SERS) offers very high selectivity and sensitivity along with the highly informative spectral characteristics of Raman spectroscopy. With all these properties, SERS-based methods offer a feasible alternative to more common optical sensing methods. By using metallic nanostructures, SERS enables a powerful means for detection of explosives with a field applications potential. It is nondestructive in common applications and reveals vibrational and rotational fingerprints of molecular structures so that high detection specificity can be achieved for explosive particles. The detection of TNT and DNT down to 5-10 zeptograms or 15-30 molecules in solution was achieved using nanoparticle-decorated nano canals and porous SERS substrates..32,33 The utilization of cysteinemodified gold nano aggregates reached a detection level of 2 picomolar TNT in aqueous solution. ${ }^{34}$ Aside from sensitivity, these techniques were reported to detect only TNT/DNT in aqueous solution..$^{32-34}$ In another work, a direct DNT vapor detection was performed at room temperature via the incorporation of gold nanoparticles (Au-NPs); UV-assisted photochemical reduction method was used for gold nanoparticle synthesis which subsequently self-assembled on a glass slide as used for SERS substrate. ${ }^{35}$ In a recent review by Zapata et al. ${ }^{36}$ on SERS detection of explosives, it has been mentioned that a matter not deeply studied is the possible interference to Raman spectra by almost any chemical compound when the metal surface is not functionalized because a majority of researchers used standard solutions of explosives instead of real samples where SERS signal should uniquely come from the molecules of the tested explosive. Another serious concern raised by the same authors is that further research in functionalization of SERS substrates is required because, up until now, these functionalizations have been widely tested only for TNT and secondarily DNT, where the rest of the explosives have been scarcely studied. ${ }^{36}$
Several assays have been developed for rapid on-site detection of RDX; however in the nineties, the single published method for colorimetric nitramines assay was not capable of distinguishing RDX from HMX. ${ }^{37}$ Usually, a single technique may not distinguish RDX from HMX having a similar structure, e.g., simultaneous identification and quantification of nitrocontaining explosives may require advanced chemometric data treatment of cyclic voltammetry at screen-printed electrodes. $^{38}$ The hydrolysis of high explosives under alkaline conditions and the degradation kinetics of nitro-explosives have been studied to reveal that alkaline hydrolysis of HMX is 10 times slower than that of RDX. ${ }^{39}$ With the advantage of different hydrolysis kinetics of RDX and HMX, differentiation and quantification of these compounds were accomplished by optical absorbance measurement in the presence of $\mathrm{N}-(1$ naphthyl)ethylenediamine (NED) and 4-aminothiophenol (4ATP) modified gold nanoparticles (AuNPs). ${ }^{5}$

In this study, we aimed to detect and quantify a wider concentration range of nitrite (generated by hydrolysis of nitramines) with SERS. After alkaline hydrolysis at room temperature, only RDX was hydrolyzed; however, at $60^{\circ} \mathrm{C}$, both RDX and HMX were hydrolyzed to obtain $\mathrm{NO}_{2}{ }^{-}$. SERS spectra were obtained for each explosive by adding silver nanoparticles (AgNPs) after the final azo-dye formation so as to increase the signal intensity. The proposed method was validated against the previously established 4-ATP-AuNPs + NED colorimetric method..$^{40}$ To the best of our knowledge, this is the first report of individual quantification of high explosives, HMX and RDX, in mixtures using SERS. Moreover, by increased charge-transfer interactions on a noble metal nanoparticle surface ${ }^{41}$ after diazotization of nitrite, the polarizability of the analyte was greatly enhanced to increase the SERS signal, enabling the novel exploitation of the 138 year old Griess method of nitrite assay.

\section{Experimental}

\section{Reagents}

Naphthylethylene diamine (NED) was purchased from Fluka. Hexadecyltrimethyl ammonium bromide (CTAB), tetrachloroauric acid $\left(\mathrm{HAuCl}_{4}\right)$, L-ascorbic acid, 4-aminothiophenol (4ATP) (synthetic grade), disodium hydrogen phosphate $\left(\mathrm{Na}_{2} \mathrm{HPO}_{4}\right)$, citric acid $\left(\mathrm{C}_{6} \mathrm{H}_{8} \mathrm{O}_{7}\right)$, hydroxylamine hydrochloride $\left(\mathrm{NH}_{2} \mathrm{OH} \cdot \mathrm{HCl}\right)$, sodium hydroxide $(\mathrm{NaOH})$ and sodium carbonate $\left(\mathrm{Na}_{2} \mathrm{CO}_{3}\right)$ were purchased from Sigma-Aldrich Chemical Co. (St. Louis, MO, USA). Sodium borohydride $\left(\mathrm{NaBH}_{4}\right)$, silver nitrate $\left(\mathrm{AgNO}_{3}\right)$, phosphoric acid $\left(\mathrm{H}_{3} \mathrm{PO}_{4}\right)$, concentrated hydrochloric acid $(\mathrm{HCl})$, ethanol $(99.9 \%)$ and acetone were purchased from Merck Co. (Darmstadt, Germany). The standard loamy clay was provided by the Forestry Faculty of Istanbul University (Istanbul, Turkey). HMX and RDX were kindly donated by Mechanical and Chemical Industry Corporation (MKEK) of Turkey.

\section{Instrumentation}

To obtain Raman spectra, DeltaNu Examiner Raman microscope with a $785 \mathrm{~nm}$ laser source, a sample holder and a CCD detector were used (DeltaNu Inc., Laramie, WY). Samples were 
measured with $150 \mathrm{~mW}$ laser power for $60 \mathrm{~s}$ acquisition time and baseline correction was applied for all measurements with an operational range of $200-2000 \mathrm{~cm}^{-1}$. For validation study, optical absorbance was measured for all samples of HMX and RDX with Agilent UV-visible spectrophotometer with a photodiode detector (Agilent Technologies Inc., Santa Clara, USA).

\section{Preparation of solutions}

Stock solutions of HMX and RDX were prepared at a concentration of $1000 \mathrm{mg} \mathrm{L}^{-1}$ in $1: 1(\mathrm{v} / \mathrm{v})$ acetone-water. Their working solutions were prepared at $2.5-50 \mathrm{mg} \mathrm{L}^{-1}$ and at $0.25-$ $10 \mathrm{mg} \mathrm{L}^{-1}$ for UV-vis and SERS measurement, respectively. The alkaline solutions to hydrolyze HMX and RDX were prepared by mixing $0.1 \mathrm{M} \mathrm{Na}_{2} \mathrm{CO}_{3}$ and $0.04 \mathrm{M} \mathrm{NaOH}$, and the acid solutions for neutralization were $1.0 \mathrm{M}$ and $5.0 \mathrm{M} \mathrm{HCl}$. To prepare phosphate-citrate buffer ( $\mathrm{pH} 3.0$ ), 0.2 $\mathrm{M}$ of $\mathrm{Na}_{2} \mathrm{HPO}_{4}$ and $0.1 \mathrm{M}$ of citric acid were mixed. A solution of $30 \mathrm{mM}$ 4-ATP was prepared in absolute ethanol, and $20 \mathrm{mM}$ of NED and $0.1 \mathrm{M}$ of $\mathrm{H}_{3} \mathrm{PO}_{4}$ solutions were prepared in deionized water.

\section{Fabrication of 4-ATP-modified gold nanorods (AuNRs)}

A two-step procedure, seed-mediated growth technique, ${ }^{42}$ was followed to fabricate gold nanorod particles. In the first step, seed solution was prepared by mixing $250 \mu \mathrm{L}$ of $0.01 \mathrm{M} \mathrm{HAuCl}_{4}$ and $7.5 \mathrm{~mL}$ of $0.1 \mathrm{M}$ CTAB solution. To this mixture, $600 \mu \mathrm{L}$ of $0.01 \mathrm{M}$ ice-cold $\mathrm{NaBH}_{4}$ was added rapidly to start the reduction of gold(III), and this solution was allowed to stand for $30 \mathrm{~min}$ to form seeds. In the second step, to prepare rod-shaped nanoparticles, growth solutions were prepared by mixing $4.75 \mathrm{~mL}$ of $0.1 \mathrm{M} \mathrm{CTAB}, 500 \mu \mathrm{L}$ of $0.01 \mathrm{M} \mathrm{HAuCl}_{4}$ and $60 \mu \mathrm{L}$ of $0.01 \mathrm{M}$ $\mathrm{AgNO}_{3}$, respectively, and the resulting color was deep yellow color. After a minute of waiting, $100 \mu \mathrm{L}$ of ascorbic acid (AA) was added and this solution turned colorless. To get the final solution, $10 \mu \mathrm{L}$ of seed solution was added to the mixture and later, this final solution was allowed to stand for 1 hour at $30^{\circ} \mathrm{C}$ for the growth of nanorod particles. The color of the solution changed to dark blue as a confirmation of the growth process. For the modification of gold nanorod particles, nanorod solution was washed with ethanol and then let to stand overnight in $30 \mathrm{mM}$ of 4-ATP solution. At the end of this time, 4-ATPmodified AuNR particles were transferred to a phosphatecitrate buffer $(\mathrm{pH} 3.0)$ solution to match the $\mathrm{pH}$ of the reaction medium.

\section{Preparation of silver nanoparticles (AgNPs)}

To prepare silver nanoparticles, the method of hydroxylamine reduction of silver nitrate ${ }^{43}$ in alkaline medium was chosen. The reaction sequence is important for the formation of hydroxylamine-silver ion complex followed by the reduction of silver(I) ions. For this purpose, firstly a $90 \mathrm{~mL}$-volume solution was prepared by dissolving $10 \mathrm{mg}$ of hydroxylamine hydrochloride and $11 \mathrm{mg}$ of sodium hydroxide. Then, $17 \mathrm{mg}$ of silver nitrate was dissolved in $10 \mathrm{~mL}$ deionized water. To form SERS-active AgNPs, the silver nitrate solution was added to the first solution and stirred mildly at room temperature. The final mixture was kept in the dark for 3 hours and at the end of this time, a green color was observed as proof of AgNPs (color depending on the size and shape of nanoparticles). Before use, a volume of $1 \mathrm{~mL}$ of silver nanoparticles was concentrated 10 times by centrifugation at $13500 \mathrm{rpm}$ for 10 minutes.

\section{Proposed SERS assay for HMX/RDX detection}

A two-step reaction was employed (the alkaline hydrolysis of HMX and RDX solutions and then neutralization of the alkaline samples) to obtain $\mathrm{NO}_{2}{ }^{-}$from nitramines. In alkaline hydrolysis, $2 \mathrm{~mL}$ of the sample solution was mixed with $2 \mathrm{~mL}$ of hydrolysis solution for a period of 30 minutes. Although HMX solutions were hydrolyzed only at a temperature of $60{ }^{\circ} \mathrm{C}$, RDX solutions did not require a high temperature for the formation of $\mathrm{NO}_{2}{ }^{-}$and room temperature was enough for their hydrolysis. After hydrolysis, the alkaline samples were neutralized with $\mathrm{HCl}$. To prevent sudden $\mathrm{pH}$ drops, after adding $0.5 \mathrm{~mL}$ of $1 \mathrm{M}$ $\mathrm{HCl}, 0.6 \mathrm{~mL}$ of $5 \mathrm{M} \mathrm{HCl}$ was added in $100 \mu \mathrm{L}$ portions. For the SERS measurement, a volume of $510 \mu \mathrm{L}$ hydrolyzed sample was mixed with $100 \mu \mathrm{L}$ of 4-ATP-AuNPs, $100 \mu \mathrm{L}$ of $1 \mathrm{M} \mathrm{H}_{3} \mathrm{PO}_{4}$ and 50 $\mu \mathrm{L}$ of $20 \mathrm{mM}$ NED in the given order. After 30 minutes, a volume of $200 \mu \mathrm{L}$ was taken from this solution and mixed with $20 \mu \mathrm{L}$ of concentrated AgNPs to take SERS spectra. Finally, the intensity difference between the wavenumbers of $1262 \mathrm{~cm}^{-1}$ and 1286 $\mathrm{cm}^{-1}$ was recorded for RDX and HMX individually. SERS signal enhancement studies (with and without AgNPs) were also performed with measurements between $1262 \mathrm{~cm}^{-1}$ and $1286 \mathrm{~cm}^{-1}$ wavenumbers.

\section{Spectrophotometric measurement of $\mathrm{HMX} / \mathrm{RDX}$}

The measurements using an UV-visible spectrophotometer were performed for the validation of the proposed method. For this purpose, the method presented by Üzer et al. was employed with a slight change. ${ }^{\mathbf{4}}$ Except for the preparation of gold nanoparticles, other experimental steps remained the same. Instead of classical citrate reduction method, AuNPs were fabricated with the seed-mediated growth technique and were not formed in spherical shape. Then, the gold nanorod particles were modified with $30 \mathrm{mM}$ of 4-ATP, which was 3 times more concentrated than in the presented assay, and they were taken into phosphate-citrate buffer ( $\mathrm{pH} 3$ ) before use. Other steps were followed as mentioned, ${ }^{40}$ and absorbance was recorded at $565 \mathrm{~nm}$ against a reagent blank.

\section{Recovery from artificially contaminated clay soil}

The standard loamy clay soil consists of $19.9 \%$ soil dust, $28.2 \%$ clay, and $51.9 \%$ sand. Each of the proposed methods was applied to $2 \mathrm{~g}$ of soil which was artificially contaminated with $2.5 \mathrm{~mL}$ of $200 \mathrm{mg} \mathrm{L}^{-1} \mathrm{RDX}$ and $2.5 \mathrm{~mL}$ of $200 \mathrm{mg} \mathrm{L}^{-1} \mathrm{HMX}$. After evaporation of the solvent, the dried soil was extracted with 25 $\mathrm{mL}$ of acetone with successive portions of the solvent. Then, the combined extracts were diluted with deionized water in a ratio of $1: 1$. Assuming $100 \%$ yield, the expected final concentration of HMX and RDX was $10 \mathrm{mg} \mathrm{L}^{-1}$ after extraction. To show the effectiveness of the method, UV-vis and SERS measurements were performed, and the results were compared. 


\section{Results and discussion}

\section{Fabrication of gold nanorod and silver nanoparticles}

Gold nanorod (AgNR) particles were fabricated for both UV-vis spectroscopy and SERS analysis of RDX and HMX determination. The absorption spectrum together with TEM image (inset) informing about geometric shapes and optical characteristics of AuNRs were given in Fig. 1. The length and width of the synthesized gold nanorods were determined as $45 \mathrm{~nm}$ and $15 \mathrm{~nm}$, respectively. The plasmon bands of Au nanorods were determined for the transverse plasmon $(524 \mathrm{~nm})$ and the longitudinal plasmon (665 nm). AuNPs were modified with 4-ATP, and after diazotization with nitrite, the diazonium salt was reacted with NED to form an intensely colored azo-dye. This colored reaction product was analyzed using both UV-vis spectrophotometry and SERS.

AgNPs were fabricated to generate a strong Raman scattering for RDX and HMX determination. The TEM image of AgNPs was given in Fig. 2 (inset), together with their typical UV-vis spectrum. As shown in Fig. 2, the spherical Ag nanoparticles have uniform morphology, with an average diameter of $35 \mathrm{~nm}$. Optical properties of $\mathrm{Ag}$ nanoparticles were determined by the excitation of plasmon resonances.

AuNPs and AgNPs enhance SERS signals when they form aggregates due to the coupling of the electromagnetic field. Several theoretical and experimental results have shown the importance of aggregation on enhancement. ${ }^{\mathbf{4 4 , 4 5}}$ AgNPs increase the SERS signal by about $10^{2}$ times, because in SERS, the Raman vibrational modes of an analyte molecule in close proximity to a rough noble metal surface are significantly enhanced. ${ }^{46}$ The SERS activity of aggregated colloids critically depends on the molar ratio of $\mathrm{Ag}$ to $\mathrm{Au}$; e.g., with an increase of the $\mathrm{Au}$ molar fraction in bimetallic ( $\mathrm{Ag} / \mathrm{Au})$ nanoparticles, the SERS activity may reach maximal intensities being 10 times stronger than that of Ag colloids alone. ${ }^{47}$ Surface-enhanced Raman scattering at extremely high enhancement levels can occur for molecules attached to silver and gold nanoclusters, giving rise to strongly enhanced and highly confined local optical fields. ${ }^{48}$ Nanostructures and nanoparticle assemblies with nanoscale gaps have been found to be the most efficient substrates owing to

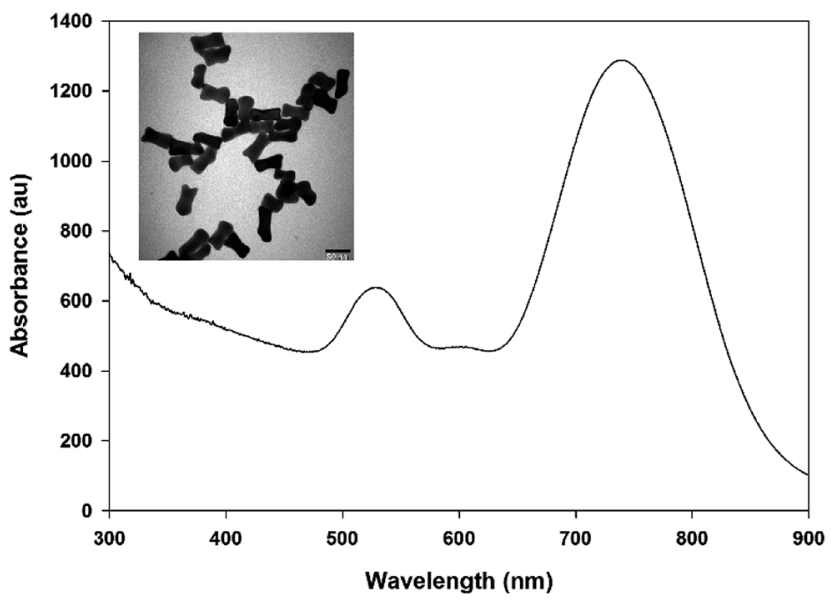

Fig. 1 UV spectrum and TEM image of Au-rod nanoparticles.

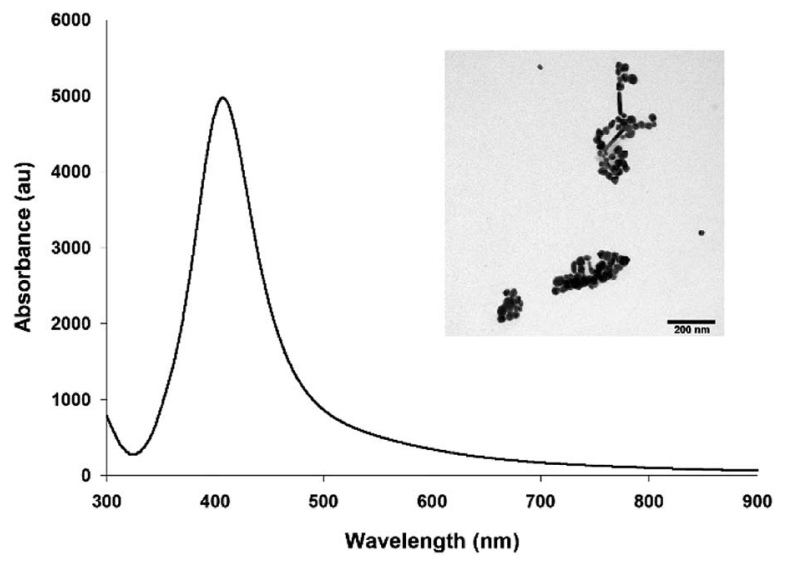

Fig. 2 UV spectrum and TEM image of Ag nanoparticles.

junction plasmons created in the gaps. Aggregated colloidal particles have localized areas of intense local fields, or 'hot spots', that may give rise to the largest enhancement factors. ${ }^{\mathbf{4 9}}$ Signal enhancement studies (with and without AgNPs) were performed with measurements between $1262 \mathrm{~cm}^{-1}$ and 1286 $\mathrm{cm}^{-1}$ wavenumbers in SERS. In order to observe a significant variation in intensity, samples with and without AgNPs were analyzed using 5 repetitive measurements. The SERS intensities were found as $13488 \pm 1229$ in samples with AgNPs and $152 \pm$ 34 in samples without AgNPs, revealing the fact that AgNPs had an important role in SERS signal enhancement.

\section{Preparation of 4-ATP-modified AuNRs}

Self-assembled monolayer (SAM) procedure has been commonly preferred for derivatization method due to its simplicity, versatility, and homogeneity. ${ }^{50,51}$ SAM layers have been used as protective groups for the stabilization of nanoparticles $^{52}$ and for the attachment of suitable modifiers to noble metal surfaces. The strength of the chemical bond between AuNRs and the SAM layer has been documented, and the strong bond prevents undesired chemical displacement reactions. ${ }^{53}$

The amine groups of 4-ATP molecules were converted to the corresponding ammonium cations (i.e. conjugate acid) at acidic pH. The ammonium form stabilized AuNRs as a result of electrostatic repulsion. Since 4-ATP bonded to AuNRs surface via the thiol group $\left(\mathrm{Au}-\mathrm{S}-\mathrm{ArNH}_{2}\right)$, its free aromatic amine group could be easily converted to the corresponding diazonium salt upon reaction with nitrite $\left(\mathrm{Au}-\mathrm{S}-\mathrm{Ar}-\mathrm{N}=\mathrm{N}^{+}\right)$. In this study, the source of nitrite was the hydrolysis of military-purpose explosive nitramines (RDX and HMX). The diazonium salt was further stabilized upon coupling with NED to intensify charge-transfer interactions that caused an increase in both optical absorbance and SERS signals. The incorporation of NED caused strong charge-transfer interactions at Au surfaces and a bathochromic shift in the SPR absorption of AuNRs. ${ }^{40-54}$

\section{Determination of RDX and HMX concentrations using UV-vis spectroscopy}

The developed absorbance-based method consisted of hydrolysis of RDX/HMX, followed by spectrophotometric detection of 
their hydrolysis products. At alkaline $\mathrm{pH}, \mathrm{RDX} / \mathrm{HMX}$ was converted to nitrite and the colorimetric analysis of nitrite was performed with 4-ATP-AuNRs + NED reaction. For this purpose, RDX and HMX working solutions in acetone-water at 2.50$50.00 \mathrm{mg} \mathrm{L}^{-1}$ concentrations were prepared and analyzed with UV-vis spectroscopy. The main difference between RDX and HMX was that RDX was hydrolyzed both at room temperature and at $60^{\circ} \mathrm{C}$ while HMX could only be hydrolyzed at $60^{\circ} \mathrm{C}$ so as to enable their differential kinetic-spectrophotometric determination.

The linear calibration curve between $2.50-50.00 \mathrm{mg} \mathrm{L}^{-1}$ concentrations of RDX was:

$$
A_{565}=0.005 C_{\mathrm{RDX}}-0.015(N=3, r=0.999)
$$

The limit of detection (LOD) was calculated as 3.3 times the standard deviation of the noise: $\sigma_{\mathrm{bl}}$ (i.e. method dispersion at the blank level) divided by the slope of the calibration curve $(\mathrm{m})$ for the analyte (drawn as response signal versus concentration); $\mathrm{LOD}=3.3 \sigma_{\mathrm{bl}} / m$. The limit of quantification (LOQ) is defined as: $\mathrm{LOQ}=10 \sigma_{\mathrm{bl}} / m$. Thus, LOQ represents the smallest concentration of analyte that can be quantified with a confidence level of $95 \%$, and corresponds to the analyte concentration for which the signal-to-noise ratio is equal to $10 .^{55}$ The LOD and LOQ for RDX were found as $1.54 \mathrm{mg} \mathrm{L}^{-1}$ and $5.14 \mathrm{mg} \mathrm{L}^{-1}$, respectively.

The linear calibration curve between $2.5-50 \mathrm{mg} \mathrm{L}^{-1}$ concentrations of HMX was:

$$
A_{565}=0.007 C_{\mathrm{HMX}}-0.033(N=3, r=0.979)
$$

The LOD and LOQ for HMX were calculated as $0.68 \mathrm{mg} \mathrm{L} \mathrm{L}^{-1}$ and $2.28 \mathrm{mg} \mathrm{L}^{-1}$, respectively.

\section{Determination of RDX and HMX concentrations using SERS}

As is apparent from the spectra in Fig. 3 and 4, the surface of AuNRs was successfully modified with 4-ATP, followed by diazotization-coupling with nitrite and NED. The SERS quantification of RDX/HMX was made by measuring the height of the maximum intensity Raman signal at $1286 \mathrm{~cm}^{-1}$, being the most concentration-responsive band (as seen in Fig. 3 and 4). AgNPs were used for SERS signal enhancement. The band at $1262 \mathrm{~cm}^{-1}$ (as the lower limit of intensity difference recording) was previously identified for intact RDX, possibly arising from $\mathrm{CH}_{2}$ scissoring and $\mathrm{N}-\mathrm{N}$ stretch vibration, ${ }^{56-58}$ however in this work, nitramines were hydrolytically degraded to nitrite, undergoing diazotization-coupling. In the presence of $\mathrm{NO}_{2}{ }^{-}$emerging as the hydrolysis product, 4-ATP-modified AuNRs were diazotized, and the final azo-dye formed as a result of NED coupling yielded the most concentration-dependent bands at $1286 \mathrm{~cm}^{-1}$, enabling the construction of a linear calibration curve between original RDX concentration and observed SERS intensity (Fig. 3). This strong band suitable for quantification can possibly be ascribed to $\{\delta(\mathrm{CCH})+\delta(\mathrm{NCC})\}$ within phenyl rings. ${ }^{59}$ On the other hand, the relatively strong band at 1170-1172 $\mathrm{cm}^{-1}$ for HMX and RDX may be ascribed to $\nu(\mathrm{CNN})$ with phenyl rings, while the weaker

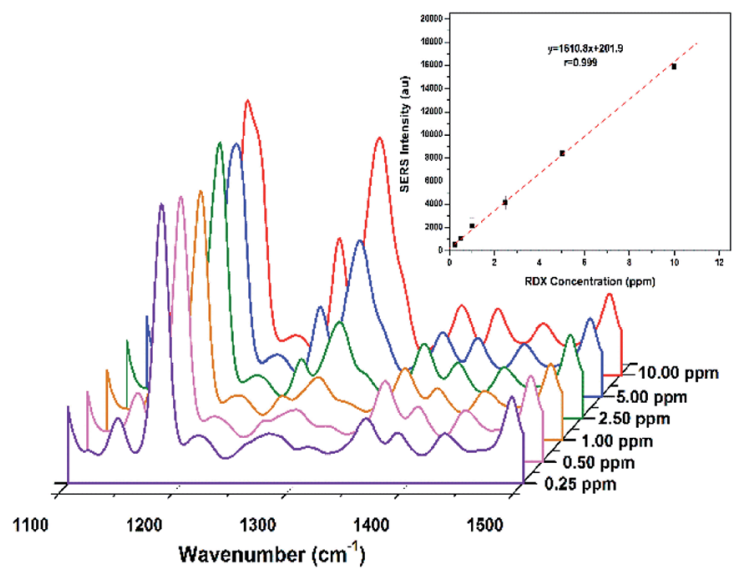

Fig. 3 SERS spectrum and calibration curve of RDX in a concentration range $0.25-10 \mathrm{mg} \mathrm{L}^{-1}$.

bands appearing at 1392 and $1431 \mathrm{~cm}^{-1}$ in both spectra (Fig. 3 and 4) to $\nu(\mathrm{C}-\mathrm{C})$ within $\mathrm{NED}$ coupled to $\mathrm{N}=\mathrm{N}$ stretch and $\nu(\mathrm{NN})$ of trans-isomers, respectively. ${ }^{\mathbf{4 6 , 5 9}}$ The linear concentration range for RDX was between $0.25 \mathrm{mg} \mathrm{L}^{-1}$ and $10.0 \mathrm{mg} \mathrm{L}^{-1}$. The linear equation for RDX calibration was:

$$
I_{\mathrm{SERS}}=1611 C_{\mathrm{RDX}}+202(N=3, r=0.999)
$$

The LOD and the LOQ for RDX were found as $0.39 \mathrm{mg} \mathrm{\textrm {L } ^ { - 1 }}$ and $1.29 \mathrm{mg} \mathrm{L}^{-1}$, respectively.

The spectra derived from the reaction of modified AuNRs with HMX hydrolysis product (Fig. 4) were evaluated likewise by using the SERS signal intensity at $1286 \mathrm{~cm}^{-1}$. The linear concentration interval for HMX was between $0.25 \mathrm{mg} \mathrm{L}^{-1}$ and $10.0 \mathrm{mg} \mathrm{\textrm {L } ^ { - 1 }}$. The equation for HMX calibration was:

$$
I_{\mathrm{SERS}}=1333 C_{\mathrm{HMX}}+1364(N=3, r=0.990)
$$

The LOD and the LOQ for HMX were found as $0.61 \mathrm{mg} \mathrm{\textrm {L } ^ { - 1 }}$ and $2.05 \mathrm{mg} \mathrm{L}^{-1}$, respectively.

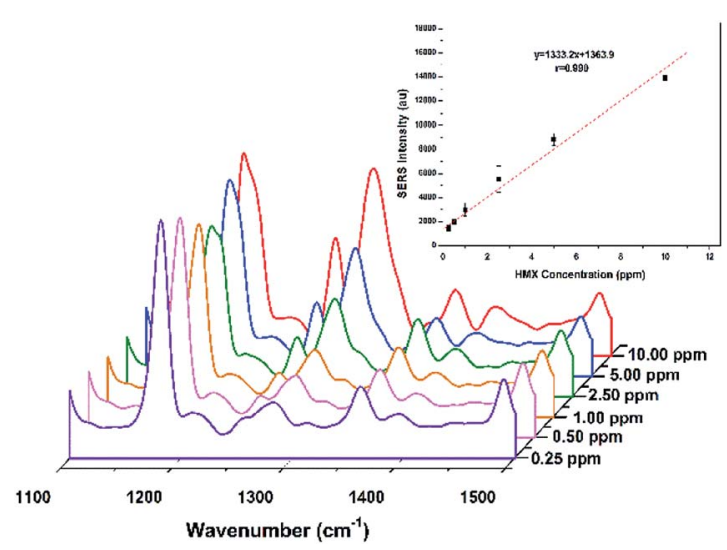

Fig. 4 SERS spectrum and calibration curve of HMX in a concentration range $0.25-10 \mathrm{mgL}^{-1}$. 


\section{UV-vis spectroscopy and SERS determination of RDX and} HMX for method validation

SERS based method for RDX and HMX was validated against the reference UV-vis analytical method using standard solutions and (RDX + HMX) mixtures in acetone-water on $N=3$ repetitive analyses. Significant differences were not found between the precision and accuracy of results (Table 1 ), where $t$ - and $F$-tests were used for comparing population means and variances, respectively. The confidence levels used in validation of both RDX and HMX were 95\%, for $t$ - and $F$-tests.

The relative standard deviation (RSD, \%) of intra-assay absorbance measurements for RDX (following hydrolysis at room temperature) and $\mathrm{HMX}$ (at $60{ }^{\circ} \mathrm{C}$ ) were $3.35 \%$ and $2.28 \%$, respectively. The RSD of inter-assay absorbance measurements for RDX (at room temperature) and $\mathrm{HMX}$ (at $60{ }^{\circ} \mathrm{C}$ ) were found as $2.89 \%$ and $0.97 \%$, respectively.

The RSD (\%) of intra-assay SERS measurements for RDX (at room temperature) and $\mathrm{HMX}$ (at $60{ }^{\circ} \mathrm{C}$ ) were $8.89 \%$ and $6.72 \%$, respectively. The RSD of inter-assay SERS measurements for RDX (at room temperature) and HMX (at $60{ }^{\circ} \mathrm{C}$ ) were found as $10.32 \%$ and $7.62 \%$, respectively. Although these coefficients of variation may seem inferior relative to those of UV-vis assays, they may be compared to the precision data of Zhang et al. ${ }^{\mathbf{4 6}}$ who used a shell-isolated nanoparticle-enhanced Raman spectroscopic assay for nitrite with RSDs for $N=5$ replicate measurements $\leq 14.5 \%$.

\section{UV-vis spectroscopy and SERS determination of RDX and HMX in soil sample}

Due to the specificity of the diazotization-coupling reaction on noble metal nanoparticle substrates, it has been established by Zhang et al. ${ }^{46}$ that common soil ions do not interfere with the SERS determination of nitrite. The analytical performance of the developed assay for RDX and HMX was evaluated with a soil sample artificially contaminated with a mixture of RDX and HMX after acetone leaching of the adsorbed nitramines from soil. The recovery of RDX component found with the UV-vis

Table 1 Statistical comparison of the UV-vis method with SERS for the determination of RDX and HMX

\begin{tabular}{llllllll}
\hline Analyte & Method & $\mathrm{SD}(\sigma)$ & $S^{a, b}$ & $t^{a, b}$ & $t_{\text {table }}$ & $F^{b}$ & $F_{\text {table }}$ \\
\hline RDX & UV-vis & 0.309 & 0.388 & 1.754 & 2.776 & 6.172 & 19.0 \\
& SERS & 0.454 & & & & & \\
HMX & UV-vis & 0.242 & 0.317 & 0.461 & 2.776 & 2.971 & 19.0 \\
& SERS & 0.377 & & & & & \\
RDX $^{c}$ & UV-vis & 0.685 & 0.511 & 0.625 & 2.776 & 0.546 & 19.0 \\
& SERS & 0.231 & & & & & \\
HMX $^{d}$ & UV-vis & 1.079 & 0.787 & 0.473 & 2.776 & 2.946 & 19.0 \\
& SERS & 0.272 & & & & &
\end{tabular}

${ }^{a} S^{2}=\left\{\left(N_{1}-1\right) S_{1}{ }^{2}+\left(N_{2}-1\right) S_{2}{ }^{2}\right\} /\left(N_{1}+N_{2}-2\right)$ and $t=\left(\bar{a}_{1}-\bar{a}_{2}\right) /\left\{S\left(1 / N_{1}+\right.\right.$ $\left.\left.1 / N_{2}\right)^{1 / 2}\right\}$, where $S$ is the pooled standard deviation, $S_{1}$ and $S_{2}$ are the standard deviations of the two populations with sample sizes of $N_{1}$ and $N_{2}$, and sample means of $\bar{a}_{1}$ and $\bar{a}_{2}$, respectively $\left(t\right.$ has $\left(N_{1}+N_{2}-\right.$ 2) degrees of freedom); here, $N_{1}=N_{2}=3 .{ }^{b}$ Statistical comparison made on paired data produced with UV-vis and SERS methods. ${ }^{c}$ RDX component in mixture. ${ }^{d}$ HMX component in mixture. spectroscopic method was $(93.1 \pm 6.0) \%$, and of HMX component $(98.7 \pm 10.8) \%(N=3)$. On the other hand, the corresponding percentages found with the SERS-based method were $95.9 \pm 4.6$ for RDX and $101.9 \pm 5.4$ for $\operatorname{HMX}(N=3)$. Consequently, similar results between UV-vis spectroscopy and SERS showed that the developed methods could be applied to real soil samples.

In this study, both RDX and HMX explosives were determined in different concentration ranges using the two spectroscopic techniques; UV-vis spectroscopy and SERS. The obtained results were evaluated through analytical performance parameters such as calibration range, LOD, LOQ, RSD\%, and recovery. The linear calibration curves were obtained between $2.50 \mathrm{mg} \mathrm{L}^{-1}$ and $50.00 \mathrm{mg} \mathrm{L}^{-1}$ for UV-vis spectroscopy, whereas between $0.25 \mathrm{mg} \mathrm{L}^{-1}$ and $10.0 \mathrm{mg} \mathrm{L}^{-1}$ for SERS for both RDX and HMX analysis. The RDX detection limit was found to be higher than $1 \mathrm{mg} \mathrm{L}^{-1}$ in UV-vis spectroscopy, but lower than this value in SERS. On the other hand, HMX detection limit was found to be lower than $1 \mathrm{mg} \mathrm{L^{-1 }}$ in both analysis techniques. The obtained RSD\% values from UV-vis spectroscopy (at about $3 \%$ ) were compared to those from SERS (at about 10\%), showing that the colorimetric procedure was more precise. The recoveries obtained for RDX and HMX using both methods exceeded $90 \%$, showing good accuracy.

\section{Comparison of analytical performance with other instrumental methods}

RDX has been analyzed by various types of spectroscopic, chromatographic and colorimetric techniques such as UV-vis spectroscopy, ${ }^{40}$ SERS, ${ }^{57,60}$ ion mobility spectroscopy (IMS), ${ }^{61}$ fluorescence quenching, ${ }^{62}$ mass spectroscopy, ${ }^{63}$ surface plasmon resonance (SPR). ${ }^{64} \mathrm{HMX}$ has been also detected especially with fluorescence spectroscopy, ${ }^{65}$ SERS,${ }^{60}$ mass spectroscopy, ${ }^{63}$ nuclear quadrupole resonance, ${ }^{\mathbf{6}}$ and colorimetric techniques. ${ }^{67,68}$ Many of these techniques require equipped substrate materials such as chips, ${ }^{69,70}$ nanoparticles, ${ }^{56,71}$ polymers ${ }^{62}$ and films. ${ }^{72}$ Both of the procedures used in this work (i.e. colorimetry and SERS) require Au nanoparticles for spectroscopic response. AgNPs were merely used for SERS measurement to stabilize and enhance the specific Raman signals of derivatized nitrite.

Balakrishnan et al. ${ }^{73}$ hydrolyzed RDX and HMX in aqueous solution ( $\mathrm{pH}$ 10-12.3), and found that nitramine removal was accompanied by formation of one molar equivalent of nitrite along with other products, where the parent nitramines were analyzed by HPLC/PDA and nitrite was determined by capillary electrophoresis. As for colorimetry, one of the oldest tests ${ }^{74}$ took advantage of the fact that cyclic nitramines liberated a fractional amount of their nitrogen content as nitric oxide (NO) which complexed with $\mathrm{Fe}(\mathrm{II})$ ions in strong $\mathrm{H}_{2} \mathrm{SO}_{4}$ medium, which may cause health hazards in the analytical laboratory. Unfortunately, the sensitivity of this test was quite low (e.g., the molar absorptivity at $525 \mathrm{~nm}$ for nitramines was approximately $\left.(4-5) \times 10^{2} \mathrm{M}^{-1} \mathrm{~cm}^{-1}\right){ }^{74}$ Jenkins et al. acidified an explosive residue mixture with acetic acid and reduced nitramines with metallic zinc to form nitrous acid, which was subsequently 
determined with the Griess reaction at a wavelength of $510 \mathrm{~nm}$; naturally a differentiation between RDX and HMX could not be made using this method. ${ }^{75}$ Generally in colorimetric tests, LOD values were not reported for nitramines. As for SERS-based methods, a dense nanosphere film and gold-coated polystyrene nanosphere film were used as SERS substrates for RDX and HMX detection, and the common LOD for both nitramines was $100 \mathrm{mg} \mathrm{L}^{-1} \cdot{ }^{60}$ Balaguera-Gelves et al. synthesized new SERS substrates such as ZnO nanorods deposited onto silicon and indium tin oxide to achieve LOD values of $10 \mathrm{nM}$ for 4 -aminobenzene thiol $\left(\mathrm{ABT}\right.$ ) and $9 \times 10^{-19} \mathrm{~g}$ for RDX (not reported in concentration units in a complex sample) under the spot of laser. $^{76}$

The RDX and HMX detection limits of various analytical techniques were evaluated, including $0.11 \mathrm{mg} \mathrm{L}^{-1}$ in amperometry, ${ }^{77} 0.22 \mathrm{mg} \mathrm{L}^{-1}$ in SERS, ${ }^{57} 10.2 \mathrm{mg} \mathrm{L}^{-1}$ in cyclic voltammetry, ${ }^{18} 100 \mathrm{mg} \mathrm{L}^{-1}$ in SERS, ${ }^{60}$ and $280 \mathrm{mg} \mathrm{L}^{-1}$ in microfluidic paper-based devices ${ }^{78}$ for RDX detection. HMX detection limits were achieved as $0.11 \mathrm{mg} \mathrm{L}^{-1}$ in amperometry, ${ }^{79} 11.7 \mathrm{mg} \mathrm{L}^{-1}$ in cyclic voltammetry, ${ }^{18}$ and $100 \mathrm{mg} \mathrm{L^{-1 }}$ in SERS. ${ }^{60}$ The detection limits of our UV-vis spectroscopic method were 1.54 and $0.68 \mathrm{mg} \mathrm{L}^{-1}$ for RDX and HMX, respectively, whereas the corresponding values were found as 0.39 and $0.61 \mathrm{mg} \mathrm{L}^{-1}$, respectively, in the developed SERS method. Both the sensitivity and linearity of the developed SERS method for nitramines were better than similar literature methods, added to the advantage that both RDX and HMX could be simultaneously determined after differential hydrolysis and derivatization.

Assuming one-to-one stoichiometry for nitramines to hydrolytically degrade into nitrite, ${ }^{73}$ we report in this work LOD values less than $2 \mu \mathrm{M}$ for RDX and therefore less than $2 \mu \mathrm{M}$ for nitrite, whereas Kim et al. ${ }^{80}$ reported an LOD $>20 \mu \mathrm{M} \mathrm{NO}_{2}{ }^{-}$, using a SERS substrate composed of diazotized 4-ATP-modified AuNPs adsorbed on a glass capillary, without diazotizationcoupling to phenolic compounds. However these authors qualitatively reported the strengthening of Raman bands upon phenolic coupling to the initially formed diazonium salt, ${ }^{\mathbf{8 0}}$ showing the importance of the influence of charge-transfer interactions on SERS signals. On the other hand, as opposed to the AuNPs/SiO ${ }_{2}$-enhanced Raman spectroscopic determination method of nitrite developed by Zhang et al. ${ }^{46}$ making use of the diazotization-coupling reagents (sulfanilamide/ diphenylamine) adsorbed onto nanoparticles which do not enable a complete charge-transfer interaction of the formed azo-dye with the underlying nanoparticles, our method covalently attached the diazotization reagents onto 4-ATPfunctionalized AuNPs. Thus, the intensified charge-transfer interactions in our case may be responsible for the enhanced SERS signals, partly explaining the lower LOD and higher reproducibility/linearity we achieved.

\section{Conclusions}

As a less studied subject, there is an urgent need for noble metal nanoparticle surfaces to be functionalized as suitable SERS substrates for the selective detection/quantification of nitramine explosives. Simultaneous quantification of HMX and
RDX was successfully presented with surface-enhanced Raman spectroscopy. The recovery of the method was higher than $90 \%$ for both nitramines, and by using SERS, it was shown that the limit of detection was found to be lower than $1 \mathrm{mg} \mathrm{L}^{-1}$. This developed SERS method proved to be more sensitive than colorimetric methods providing the highest molar absorptivity for nitrite, whereas it is a most sensitive method among its Raman counterparts. The method was applicable to soil samples containing explosive residues as a potential tool for sensitive screening of criminologic sites (e.g., in post-blast debris containing a small fraction of undegraded nitramine particles).

\section{Acknowledgements}

We acknowledge Prof. Dr Zekiye Suludere and Prof. Dr Demet Çetin for their kind support in obtaining TEM images.

\section{References}

1 M. López-López and C. García-Ruiz, TrAC, Trends Anal. Chem., 2014, 54, 36.

2 J. P. Agrawal, High energy materials: propellants, explosives and pyrotechnics, John Wiley \& Sons, 2010.

3 A. Üzer, E. Erçağ and R. Apak, Anal. Chim. Acta, 2008, 612, 5364.

4 M. Chaloosi, F. Gholamian and M. A. Zarei, Propellants, Explos., Pyrotech., 2001, 26, 21-25.

5 A. Hilmi, J. H. T. Luong and A. L. Nguyen, Anal. Chem., 1999, 71, 873-878.

6 C. A. Groom, A. Halasz, L. Paquet, P. D'Cruz and J. Hawari, J. Chromatogr. A, 2003, 999, 17-22.

7 B. Zhang, X. Pan, G. P. Cobb and T. A. Anderson, J. Chromatogr. B: Anal. Technol. Biomed. Life Sci., 2005, 824, 277-282.

8 X. Pan, B. Zhang and G. P. Cobb, Talanta, 2005, 67, 816-823. 9 R. Waddell, D. E. Dale, M. Monagle and S. A. Smith, J. Chromatogr. A, 2005, 1062, 125-131.

10 M. E. Walsh, Talanta, 2001, 54, 427-438.

11 R. L. Marple and W. R. LaCourse, Talanta, 2005, 66, 581-590.

12 X. Pan, B. Zhang, S. B. Cox, T. A. Anderson and G. P. Cobb, J. Chromatogr. A, 2006, 1107, 2-8.

13 D. A. Cassada, S. J. Monson, D. D. Snow and R. F. Spalding, J. Chromatogr. A, 1999, 844, 87-95.

14 R. L. Marple and W. R. LaCourse, Anal. Chem., 2005, 77, 6709-6714.

15 T. Khayamian, M. Tabrizchi and M. T. Jafari, Talanta, 2003, 59, 327-333.

16 S. Y. Ly, D. H. Kim and M. H. Kim, Talanta, 2002, 58, 919926.

17 N. Pon Saravanan, S. Venugopalan, N. Senthilkumar, P. Santhosh, B. Kavita and H. G. Prabu, Talanta, 2006, 69, 656-662.

18 A. Üzer, Ş. Sağlam, Y. Tekdemir, B. Ustamehmetoğlu, E. Sezer, E. Erçağ and R. Apak, Talanta, 2013, 115, 768-778.

19 J. Yinon, Forensic and environmental detection of explosives, John Wiley \& Sons, 1999. 
20 S. Wallin, A. Pettersson, H. Östmark and A. Hobro, Anal. Bioanal. Chem., 2009, 395, 259-274.

21 F. C. Thorley, K. J. Baldwin, D. C. Lee and D. N. Batchelder, J. Raman Spectrosc., 2006, 37, 335-341.

22 S. Wallin, A. Pettersson, H. Önnerud, H. Östmark, M. Nordberg, E. Ceco, A. Ehlerding, I. Johansson and P. Käck, Proc. SPIE, 2012, 8358, 83580.

23 M. L. Ramirez-Cedeno, W. Ortiz-Rivera, L. C. PachecoLondono and S. P. Hernandez-Rivera, IEEE Sens. J., 2010, 10, 693-698.

24 N. Gupta and R. Dahmani, Spectrochim. Acta Part A: Mol and Biomol. Spectrosc, 2000, 56, 1453-1456.

25 M. L. Lewis, I. R. Lewis and P. R. Griffiths, Appl. Spectrosc., 2004, 58, 420-427.

26 M. L. Lewis, I. R. Lewis and P. R. Griffiths, Vib. Spectrosc., 2005, 38, 17-28.

27 M. Mordmueller, C. Bohling, A. John and W. Schade, Proc. SPIE, 2009, 7484, 74840F.

28 J. Moros, J. A. Lorenzo, P. Lucena, L. M. Tobaria and J. J. Laserna, Anal. Chem., 2010, 82, 1389-1400.

29 M. López-López, J. L. Ferrando and C. García-Ruiz, Anal. Chem., 2013, 85, 2595-2600.

30 J. Moros and J. J. Laserna, Anal. Chem., 2011, 83, 6275-6285. 31 B. Zachhuber, G. Ramer, A. Hobro, E. t. H. Chrysostom and B. Lendl, Anal. Bioanal. Chem., 2011, 400, 2439-2447.

32 H. Ko and V. V. Tsukruk, Small, 2008, 4, 1980-1984.

33 H. Ko, S. Chang and V. V. Tsukruk, ACS Nano, 2009, 3, 181188.

34 S. S. R. Dasary, A. K. Singh, D. Senapati, H. Yu and P. C. Ray, J. Am. Chem. Soc., 2009, 131, 13806-13812.

35 M. K. K. Oo, C.-F. Chang, Y. Sun and X. Fan, Analyst, 2011, 136, 2811-2817.

36 F. Zapata, M. López-López and C. García-Ruiz, Appl. Spectrosc. Rev., 2016, 51, 227-262.

37 T. F. Jenkins and M. E. Walsh, Talanta, 1992, 39, 419-428.

38 X. Cetó, A. M. O'Mahony, J. Wang and M. del Valle, Talanta, 2013, 107, 270-276.

39 H. M. Heilmann, U. Wiesmann and M. K. Stenstrom, Environ. Sci. Technol., 1996, 30, 1485-1492.

40 A. Üzer, Z. Can, İ. Akın, E. Erçağ and R. Apak, Anal. Chem., 2014, 86, 351-356.

41 W.-H. Park and Z. H. Kim, Nano Lett., 2010, 10, 4040-4048.

42 B. Nikoobakht and M. A. El-Sayed, Chem. Mater., 2003, 15, 1957-1962.

43 N. Leopold and B. Lendl, J. Phys. Chem. B, 2013, 107, 57235727.

44 P. Y. Ma, F. H Liang, X. P. Li, Q. Q. Yang, D. Wang, D. Q. Song, D. J. Gao and X. H. Wang, Food Anal. Methods, 2014, 7, 1866-1873.

45 O. Olea-Mejia, M. Fernandez-Mondragon, G. Rodriguez-de la Concha and M. Camacho-Lopez, Appl. Surf. Sci., 2015, 348, 66-70.

46 K. Zhang, Y. Hu and G. Li, Talanta, 2013, 116, 712-718.

47 Y. Cui, B. Ren, J.-L. Yao, R.-A. Gu and Z.-Q. Tian, J. Phys. Chem. B, 2006, 110, 4002-4006.

48 K. Kneipp, H. Kneipp and J. Kneipp, Acc. Chem. Res., 2006, 39, 443-450.
49 S. Lal, S. Link and N. J. Halas, Nat. Photonics, 2007, 1, 641648.

50 S. A. Kumar and S. M. Chen, Biosens. Bioelectron., 2007, 22, 3042-3050.

51 F. Li, Y. Feng, P. J. Dong and B. Tang, Biosens. Bioelectron., 2010, 25, 2084-2088.

52 T. G. Schaaff, M. N. Shafigullin, J. T. Khoury, I. Vezmar and R. L. Whetten, J. Phys. Chem. B, 2001, 105, 8785-8796.

53 C. J. Jiang, J. M. Elliott, D. J. Cardin and S. C. Tsang, Langmuir, 2009, 25, 534-541.

54 A. J. Haes and R. P. Van Duyne, J. Am. Chem. Soc., 2002, 124, 10596-10604.

55 J. Vial and A. Jardy, Anal. Chem., 1999, 71, 2672-2677.

56 T. F. Chen, S. H. Lu, A. J. Wang, D. Zheng, Z. L. Wu and Y. S. Wang, Appl. Surf. Sci., 2014, 317, 940-945.

57 N. A. Hatab, G. Eres, P. B. Hatzinger and B. H. Gu, J. Raman Spectrosc., 2010, 41, 1131-1136.

58 O. Prakash, P. Gautam, S. Kumar, P. Singh, R. K. Dani, M. K. Bharty, N. K. Singh, A. K. Ghosh, V. Deckert and R. K. Singh, RSC Adv., 2015, 5, 5571-5579.

59 K. Zhang, L. Liang, M. Huang, Y. Hu and G. Li, Microchim. Acta, 2014, 181, 1301-1308.

60 F. A. Calzzani, R. Sileshi, A. Kassu, J. M. Taguenang, A. Chowdhury, A. Sharma, P. B. Ruffin, C. Brantley and E. Edwards, P. Soc. Photo-Opt. Ins., 2008, 6945, 09451.

61 M. Tabrizchi and V. ILbeigi, J. Hazard. Mater., 2010, 176, 692-696.

62 D. Gopalakrishnan and W. R. Dichtel, J. Am. Chem. Soc., 2013, 135, 8357-8362.

63 S. Park, J. Lee, S. G. Cho, E. M. Goh, S. Lee, S. S. Koh and J. Kim, Bull. Korean Chem. Soc., 2013, 34, 3659-3664.

64 M. Riskin, R. Tel-Vered and I. Willner, Adv. Mater., 2010, 22, 1387-1391.

65 C. Wang, H. L. Huang, B. R. Bunes, N. Wu, M. Xu, X. M. Yang, L. Yu and L. Zang, Sci. Rep., 2016, 6, 25015.

66 T. N. Rudakov, P. A. Hayes, V. T. Mikhaltsevitch and W. P. Chisholm, Appl. Magn. Reson., 2004, 25, 501-512.

67 S. Semel, M. A. Laccetti and M. Roth, Anal. Chem., 1959, 31, 1050-1052.

68 S. Stevanovic and M. Mitrovic, Int. J. Environ. Anal. Chem., 1990, 40, 69-76.

69 S. Almaviva, S. Botti, L. Cantarini, R. Fantoni, S. Lecci, A. Palucci, A. Puiu and A. Rufoloni, J. Raman Spectrosc., 2014, 45, 41-46.

70 L. A. Pinnaduwage, D. L. Hedden, A. Gehl, V. I. Boiadjiev, J. E. Hawk, R. H. Farahi, T. Thundat, E. J. Houser, S. Stepnowski, R. A. McGill, L. Deel and R. T. Lareau, Rev. Sci. Instrum., 2004, 75, 4554-4557.

71 J. L. Gottfried, Appl. Opt., 2012, 51, B13-B21.

72 M. Pumera, Electrophoresis, 2006, 27, 244-256.

73 V. K. Balakrishnan, A. Halasz and J. Hawari, Environ. Sci. Technol., 2003, 37, 1838-1843.

74 M. A. Laccetti, S. Semel and M. Roth, Anal. Chem., 1959, 31, 1049-1050.

75 T. F. Jenkins, M. E. Walsh, P. W. Schumacher and P. G. Thorne, Environmental Monitoring and Hazardous Waste Site Remediation, 1995, vol. 2504, pp. 324-333. 
76 M. d. R. Balaguera-Gelves, O. J. Perales-Pérez, S. P. Singh, J. A. Jiménez, J. A. Aparicio-Bolaños and S. P. HernándezRivera, Mater. Sci. Appl., 2013, 4, 29-38.

77 A. Hilmi and J. H. T. Luong, Environ. Sci. Technol., 2000, 34, 3046-3050.
78 K. L. Peters, I. Corbin, L. M. Kaufman, K. Zreibe, L. Blanes and B. R. McCord, Anal. Methods, 2015, 7, 63-70.

79 A. Hilmi, J. H. T. Luong and A. L. Nguyen, Anal. Chem., 1999, 71, 873-878.

80 K. Kim, K. L. Kima and K. S. Shin, Analyst, 2012, 137, 38363840 . 